\title{
ADSORÇÃO DE GLIFOSATO SOBRE SOLOS E MINERAIS
}

Luís R. M. Toni, Henrique de Santana e Dimas A. M. Zaia*

Departamento de Química, Centro de Ciências Exatas, Universidade Estadual de Londrina, CP 6001, 86051-990 Londrina-PR, Brasil

Recebido em 6/4/05; aceito em 2/9/05; publicado na web em 16/2/06

\begin{abstract}
ADSORPTION OF GLYPHOSATE ON SOILS AND MINERALS. Glyphosate, an enzyme inhibitor herbicide, has been widely used around the world in agriculture. Dr. John Franz from Monsanto Corporation (USA) discovered glyphosate in 1970. It has been showed that glyphosate is strongly adsorbed by inorganic soil components especially aluminium and iron oxides, and the phosphate group is involved in this interaction. The inactivation of glyphosate in soils can last for days or even months depending on soil characteristics. The addition of phosphate from fertilizers can displace glyphosate from the soils and this could be the cause of decreased productivity of some crops.
\end{abstract}

Keywords: glyphosate; adsorption; soil.

\section{INTRODUÇÃOO}

Os herbicidas são compostos orgânicos, quimicamente sintetizados, utilizados na agricultura para controle de ervas daninhas. Quando aplicados ao sistema solo/planta fatalmente chegam ao solo devido à aplicação direta ou pela incorporação da resteva cultural, sendo classificados como micropoluentes do ponto de vista ambiental ${ }^{1,2}$.

Quando a molécula de um herbicida chega ao solo, pode sofrer os processos de degradação e/ou adsorção $0^{3-5}$. Os herbicidas adsorvidos, assim, como os seus resíduos degradados, podem sofrer um destes processos: absorção das moléculas pelas plantas ou a lixiviação das moléculas para camadas sub-superficiais do solo, podendo atingir cursos subterrâneos de água, ou permanecer como resíduos ligados ${ }^{2,3}$. A adsorção reduz a concentração dos herbicidas na fração solubilizada do solo, removendo parte de sua ação potencial. O resultado é observado pelo decréscimo da disponibilidade biológica, na aceleração da velocidade de degradação química ou, simplesmente, devido ao retardamento do movimento de lixiviação. Os efeitos observados, porém, estão relacionados diretamente com o ambiente químico presente e com a natureza do adsorvente e do adsorbato $^{5}$. A degradação e retenção dos herbicidas pelo solo podem ser influenciadas por $\mathrm{pH}$, umidade, capacidade de troca catiônica, temperatura, matéria orgânica, etc. Cada herbicida possui, ainda, um mecanismo de adsorção e degradação, que varia de acordo com suas propriedades químicas ${ }^{2,3}$.

O glifosato [n-(fosfonometil)glicina], cuja fórmula molecular é $\mathrm{C}_{3} \mathrm{H}_{8} \mathrm{NO}_{5} \mathrm{P}$ (Figura 1) é um herbicida inibidor enzimático utilizado mundialmente na agricultura. Foi descoberto em 1970 por um grupo de cientistas da Companhia Monsanto (EUA) liderados pelo Dr. J. Franz. O glifosato-isopropilamônio e o glifosato-sesquisódio são comercializados pela Monsanto Corporation, desde 1971, com o nome de Roundup, sendo que esta companhia controla $80 \%$ do mercado mundial de comércio de glifosato ${ }^{6}$. O glifosato funciona como herbicida não seletivo, sistêmico, pós-emergente. Atualmente, é comercializado em mais de cem países, sendo registrado para uso em mais de uma centena de culturas. O Brasil consome 150 milhões de L/ano desse herbicida, representando $30 \%$ em volume

*e-mail: damzaia@uel.br de todos os defensivos agrícolas usados no país ${ }^{6}$. Na maioria dos casos de aplicação, o glifosato não é metabolizado pela planta, razão pela qual não apresenta seletividade. Devido a isto, praticamente toda a concentração do ingrediente ativo aplicado chega ao solo na sua forma original ${ }^{2}$. Estudos realizados no meio ambien$\mathrm{te}^{7,8}$ mostram que os solos apresentaram as maiores concentrações de glifosato e de seu principal produto de decomposição, o ácido aminometilfosfônico (AMPA) (Figura 1).

O glifosato age na inibição enzimática das plantas, através da enzima 5-enolpiruvilchiquimato-3-fosfato sintase (EPSPs), que é responsável pela síntese dos aminoácidos aromáticos essenciais (fenilalanina, tirosina e triptofano) (Figura 2), os quais são precursores de outros produtos, como lignina, alcalóides, flavonóides, ácidos benzóicos e vitamina $\mathrm{K}^{9-11}$.<smiles>NCP(=O)(O)O</smiles>

Figura 1. Estrutura do glifosato e de seu principal produto de degradação (AMPA)

\section{ADSORÇÃO DO GLIFOSATO SOBRE SOLOS}

O solo é constituído de três fases: sólida, líquida e gasosa. A fase sólida do solo é constituída de matéria inorgânica (argilas minerais) e de matéria orgânica (em geral produto da decomposição de seres vivos). A composição da parte inorgânica do solo depende do estágio de desenvolvimento deste. A fase líquida do solo ocupa o espaço poroso do mesmo constituindo a solução do solo. Esta fase é parte de um sistema dinâmico e aberto, cuja composição é resultante das inúmeras reações que ocorrem com as outras fases que o constituem. Assim sendo, a solução do solo contém, além da água, substâncias minerais, orgânicas e gases dissolvidos. Os gases encontrados no solo são os mesmos encontrados no ar atmosférico, o que varia é sua concentração. A respiração das raízes e dos microrganismos e a decomposição da matéria orgânica são as responsáveis por esta diferença ${ }^{12}$. 

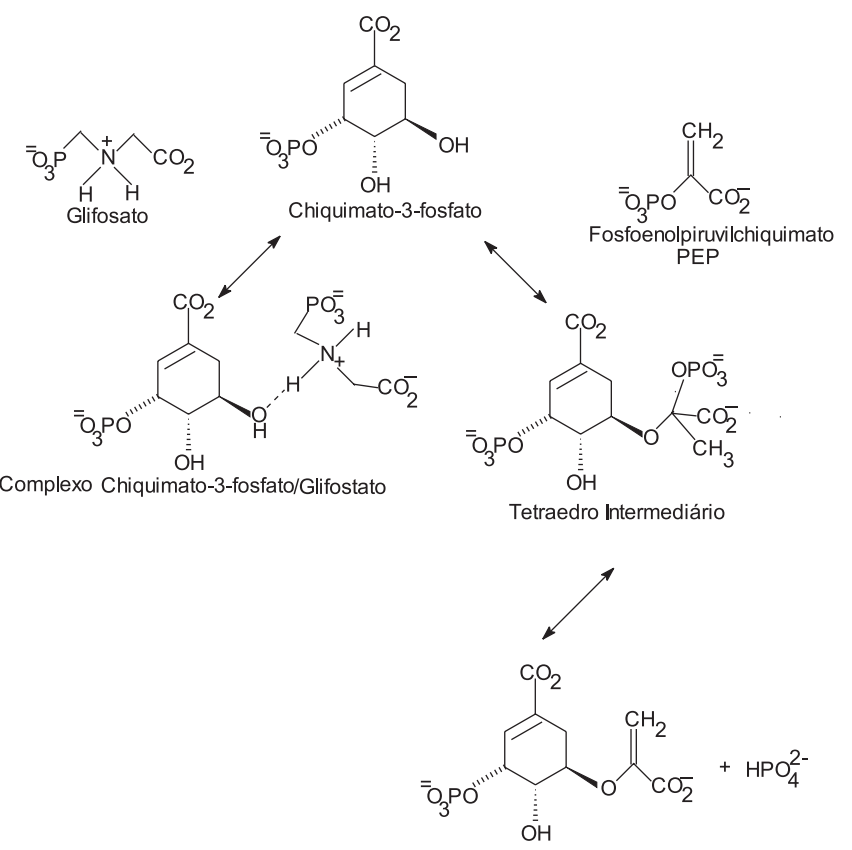

5-Enolpiruvilchiquimato-3-fosfato Fosfato

Figura 2. Mecanismo de ação do glifosato. O lado direito da figura mostra a formação do tetraedro intermediário (reação entre chiquimato-3-fosfato e PEP) para a posterior formação do 5-enolpiruvilchiquimato-3-fosfato. O lado esquerdo da figura mostra como esta reação pode ser inibida pelo glifosato

O glifosato no solo apresenta alta capacidade de adsorção e devido a isto, muitos são os estudos que tentam explicar os mecanismos de ligação entre glifosato e solo. Os mais comuns são a troca de ligantes com os óxidos de ferro e alumínio e as pontes de hidrogênio formadas entre o glifosato e as substâncias húmicas presentes no solo ${ }^{13-21}$.

Diversos autores ${ }^{3,21,22}$ estudaram o efeito do $\mathrm{pH}$ na adsorção de glifosato sobre solos. Estes autores mostraram que essa adsorção diminuiu com o aumento do $\mathrm{pH}$ da solução solo/água. Esta diminuição na adsorção foi atribuída a um aumento no número de cargas negativas do glifosato, assim como da superfície do solo, resultando em uma maior repulsão eletrostática e, conseqüentemente, na diminuição da adsorção.

Segundo Prata et $a ._{.}{ }^{20}$, o tempo de meia vida $\left(\mathrm{t}_{1 / 2}\right)$ de degradação do glifosato no solo varia com o tipo de solo e, principalmente, devido à formação de resíduos ligados e a biodegradação. Cheah $e t$ $a l .{ }^{19}$, estudando solos arenosos, encontraram $\mathrm{t}_{1 / 2}=19,2$ dias para $\mathrm{o}$ glifosato. Feng e Thompson ${ }^{13}$ mediram os $t_{1 / 2}$ do glifosato em solos de uma floresta localizada no Canadá e verificaram que este tempo variava de 45 a 60 dias. Resultados semelhantes foram encontrados por Nomura e Hilton ${ }^{3}$, estudando $t_{1 / 2}$ para solos vulcânicos do Havaí. Segundo a Agência de Proteção Ambiental-EPA/EUA ${ }^{23}$, nos solos do Texas o valor de $\mathrm{t}_{1 / 2}$ para o glifosato é pequeno (3 dias), já para solos de Iowa esse tempo é longo (141 dias).

\section{Influência da fração mineral}

Nomura e Hilton ${ }^{3}$ estudaram a adsorção e degradação de glifosato em cinco solos havaianos utilizados para cultura de canade-açúcar. Estes autores não conseguiram fazer experimentos com isotermas de adsorção, pois o glifosato adsorve em grandes quantidades nestes solos. Esta grande adsorção foi relacionada com a presença de óxidos e hidróxidos das argilas presentes nos solos. Glass ${ }^{24}$ estudou a adsorção de glifosato em três diferentes solos e mostrou que a mesma dependia da capacidade de troca catiônica (CTC) e da quantidade de argilas. Gerritse et al. ${ }^{16}$ estudaram a adsorção de glifosato em solos arenosos e observaram que a mesma aumentava com a quantidade de ferro e alumínio e diminuía com o aumento da quantidade de carbono; sendo que em solos onde os teores de $\mathrm{Fe}^{3+}$ e $\mathrm{Al}^{3+}$ são maiores que $1 \%$ o glifosato e seu principal produto de degradação, o AMPA, ficam imobilizados. Gimsing et l $^{25}$ estudaram a adsorção de glifosato e fosfato em diferentes solos e concluíram que ambos são adsorvidos fortemen-

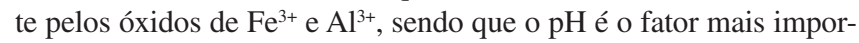
tante na adsorção destas substâncias. Morillo et al. ${ }^{22}$ mostraram que a adsorção de glifosato não estava relacionada à quantidade de argila ou CTC, mas sim às quantidades de óxidos amorfos de ferro e alumínio. Morillo et al. ${ }^{26}$ também estudaram a influência do glifosato na adsorção do $\mathrm{Cu}^{2+}$ em diferentes solos e observaram que, em geral, o glifosato diminuiu a adsorção do $\mathrm{Cu}^{2+}$ sobre os mesmos, provavelmente devido ao complexo formado entre $\mathrm{Cu}^{2+} \mathrm{e}$ glifosato. Prata et al. ${ }^{20}$ também mostraram que a adsorção de glifosato por diferentes solos estava relacionada à quantidade de óxidos de ferro e alumínio e que a matéria orgânica tinha um papel secundário. Da Cruz et al. ${ }^{21}$ estudaram a adsorção de glifosato em diferentes solos do Paraná e observaram que a adsorção depende da quantidade de argilas e CTC e que a matéria orgânica desempenha um papel secundário. De Santana et al. ${ }^{27}$, utilizando espectroscopia no infravermelho, estudaram a interação do glifosato com solos do Paraná e observaram que os grupos fosfato e carboxílico interagem com os metais $\left(\mathrm{Fe}^{3+}, \mathrm{Al}^{3+}\right)$ presentes no solo. Portanto, os dados obtidos por diversos pesquisadores mostram que não há uma concordância sobre qual fator relacionado à fração mineral (quantidade de argila, óxidos de $\mathrm{Fe}^{3+}$ e $\mathrm{Al}^{3+}$, CTC etc) é o mais importante na adsorção do glifosato sobre solos.

\section{Influência da fração orgânica}

Em geral, a matéria orgânica desempenha papel secundário na adsorção do glifosato ${ }^{3,16,20,21}$. No entanto, em alguns casos a matéria orgânica pode ter um papel importante, quando em altas concentrações.

Feng e Thompson ${ }^{13}$ estudaram a adsorção do glifosato e de seu principal produto de decomposição (AMPA) em solos de uma floresta no Canadá e observaram que mais de $90 \%$ destes compostos ficam retidos na camada orgânica superficial $(0-15 \mathrm{~cm})$. Utilizando espectroscopias de infravermelho e de fluorescência, Miano et al. ${ }^{14}$ estudaram a interação entre glifosato e substâncias húmicas. Observaram que ocorre desagregação das moléculas das substâncias húmicas com o aumento na concentração de glifosato, muito provavelmente devido às pontes de hidrogênio formadas entre o grupo fosfato do glifosato e o polímero das substâncias húmicas. Piccolo et $a l .{ }^{17}$ estudaram a adsorção de glifosato sobre substâncias húmicas extraídas de diferentes materiais (material vegetal em decomposição, solo vulcânico, carvão oxidado, lignita). Segundo estes autores, a adsorção do glifosato sobre substâncias húmicas pode ser explicada devido à presença das múltiplas pontes de hidrogênio que podem ocorrer entre vários grupos ácidos e grupos contendo oxigênio, que existem em ambas as moléculas. Os resultados obtidos por Piccolo et al. ${ }^{17}$ mostraram que a adsorção de glifosato sobre substâncias húmicas varia consideravelmente com a dimensão e a estrutura macromolecular destas substâncias, sendo que a adsorção é favorecida quando são combinados tamanho molecular e flexibilidade esteroquímica das moléculas das substâncias húmicas. Undabeytia et al. ${ }^{18}$ estudaram os mecanismos envolvidos na interação entre glifosato e substâncias húmicas que tenham sido previamente tratadas com uma solução de $\mathrm{Cu}^{2+}$. As substâncias húmicas formam complexos de es- 
fera interna com o cobre e estes complexos são deslocados pelo glifosato. No entanto, quando as substâncias húmicas são submetidas à hidrólise ácida tal efeito não ocorre. Segundo os autores, estes resultados podem ser explicados considerando-se que o $\mathrm{Cu}^{2+}$ se liga mais fortemente aos locais anteriormente ocupados pelo $\mathrm{Fe}^{3+}$ nas substâncias húmicas.

\section{ADSORÇÃO DO GLIFOSATO SOBRE ARGILAS E ÓXIDOS DE METAIS}

Como visto anteriormente, a adsorção do glifosato pelo solo é devida principalmente à sua fração inorgânica e é nessa fração que são encontradas as argilas e os óxidos.

As argilas bilaminares do grupo 1:1 são formadas pelo arranjo de uma lâmina tetraédrica, contendo o silício no centro envolvido por oxigênios, com uma lâmina octaédrica, contendo o $\mathrm{Al}^{3+}$ no centro envolvido por oxigênios e oxidrilas, sendo que o principal representante dessa classe de minerais é a caulinita $\left(\mathrm{Al}_{4} \mathrm{Si}_{4} \mathrm{O}_{10}(\mathrm{OH})_{8}\right)$. Cabe salientar que a caulinita é uma argila muito comum nos solos brasileiros ${ }^{12}$.

As argilas trilaminares do grupo 2:1 formam-se pela união de duas lâminas tetraédricas de $\mathrm{Si}$, intercaladas por uma lâmina octaédrica de $\mathrm{Al}^{3+}$, unidas pelos oxigênios apicais dos octaedros. As vermiculitas $\left.\left(\mathrm{Mg}, \mathrm{Fe}^{2+}, \mathrm{Fe}^{3+}\right)_{3}\left[(\mathrm{Si}, \mathrm{Al})_{4} \mathrm{O}_{10}\right][\mathrm{OH}]_{2} .4 \mathrm{H}_{2} \mathrm{O}\right)$; esmectitas; montmorilonitas $\left(\mathrm{m}\left\{\mathrm{Mg}_{3}\left[\mathrm{Si}_{4} \mathrm{O}_{10}\right]\left[\mathrm{OH}_{2}\right]\right\} \cdot \mathrm{p}\left\{(\mathrm{Al}, \mathrm{Fe})_{2} \cdot\left[\mathrm{Si}_{4} \mathrm{O}_{10}\right]\right.\right.$ $[\mathrm{OH}]_{2} \cdot \mathrm{nH}_{2} \mathrm{O}$, (onde a relação m:p varia entre 0,8 e 0,9 ) são as principais representantes dessa classe ${ }^{12}$.

A clorita é a principal representante das argilas tetralaminares do grupo 2:2; ela pode ser definida como sendo um mineral 2:1, similar às micas, com uma lâmina adicional octaédrica de brucita $\left(\mathrm{Mg}(\mathrm{OH})_{2}\right)^{12}$.

Os principais óxidos presentes nos solos são os de $\mathrm{Fe}^{3+}$ e $\mathrm{Al}^{3+}$, relacionados com a adsorção do glifosato pelos solos, sendo a goetita $(\alpha-\mathrm{FeO} . \mathrm{OH})$ e a hematita $\left(\alpha-\mathrm{Fe}_{2} \mathrm{O}_{3}\right)$ os óxidos de ferro mais comuns encontrados e a gibsita $\left(\mathrm{Al}(\mathrm{OH})_{3}\right)$ o óxido de alumínio mais comum. A gibsita, apesar de ser formada por um hidróxido, é considerada um óxido na química dos solos, estando incluídos nesta classe, além dos óxidos, os oxi-hidróxidos e os hidróxidos ${ }^{12}$.

\section{Adsorção de glifosato sobre argilas}

McConnel e Hossner ${ }^{28}$, utilizando técnicas de cromatografia líquida de alta eficiência, estudaram a adsorção do glifosato sobre caulinita e montmorilonita em dois pHs diferentes. Em pH 4,5 a caulinita apresentou maior adsorção de glifosato em relação à montmorilonita saturada com íons $\mathrm{Na}^{+}$, porém, em $\mathrm{pH} \mathrm{7,0}$ a montmorilonita apresentou maior adsorção de glifosato em relação à caulinita. Estudando a adsorção do glifosato em três diferentes argilas (caulinita, ilita e montmorilonita), Glass ${ }^{24}$ observou que a capacidade de adsorção do glifosato pela argila está ligada à sua capacidade de troca catiônica (CTC). As argilas que apresentaram maior e menor CTC, respectivamente, foram montmorilonita (argila trilaminar do grupo 2:1) e caulinita (argila bilamiar do grupo $1: 1)$. Conseqüentemente, a montmorilonita apresentou a maior adsorção e a caulinita, a menor adsorção de glifosato. Miles e Moye $^{29}$, estudando argilas saturadas com cátions trocáveis, observaram que a adsorção do glifosato varia de forma inversa em relação ao pH da suspensão da argila. Observaram uma adsorção muito forte e específica do glifosato pela caulinita. A caulinita foi a argila que mais adsorveu glifosato, seguida da ilita, montmorilonita e bentonita. McConnell e Hossner ${ }^{30}$ utilizaram difração de raios-X e espectroscopia no infravermelho para estudar a interação do glifosato com argilas (caulinita e esmectita) saturadas com íons
$\left(\mathrm{Al}^{3+}, \mathrm{Ca}^{2+}, \mathrm{Na}^{+}\right)$. Para as amostras de esmectita foi observada uma redução nas freqüências no infravermelho, indicando a formação de pontes de hidrogênio e no caso da caulinita não foi observada nenhuma mudança no espectro. No entanto, De Santana et al. ${ }^{27}$ utilizando soluções saturadas de glifosato observaram uma interação do grupo fosfato do glifosato com metais $\left(\mathrm{Fe}^{3+}, \mathrm{Al}^{3+}\right)$ da caulinita. Dubbin et al. ${ }^{31}$, utilizando espectroscopia de absorção de raios-X, estudaram o sistema $\mathrm{Cu}^{2+} /$ glifosato/gibsita e propuseram uma estrutura em que o grupo fosfato do glifosato interage com $\mathrm{Al}^{3+}$ da gibsita e os grupos carboxil e amina interagem com $\mathrm{Cu}^{2+}$. Da Cruz et $a l .{ }^{21}$ também estudaram a adsorção de glifosato sobre caulinita, bentonita e montmorilonita e observaram que a quantidade de glifosato adsorvido foi dependente da área superficial. Os dados obtidos por estes autores demonstraram que a bentonita foi a argila que mais adsorveu, seguida da caulinita e, por último, a montmorilonita.

Outros autores também mostraram que adsorção do glifosato sobre argilas diminui com o aumento do $\mathrm{pH}^{21,27}$. No entanto, segundo Glass ${ }^{24}$ a adsorção de glifosato sobre ilita independe do $\mathrm{pH}$.

\section{Adsorção de glifosato sobre óxidos de metais}

McConnell e Hossner ${ }^{28}$ observaram que a interação entre glifosato e goetita e hematita era dependente do $\mathrm{pH}$. Em trabalho posterior $^{30}$, esses autores verificaram que as bandas no infravermelho, atribuídas à interação entre glifosato sobre goetita, hematita e gibsita, não eram observadas. Sheals et al. ${ }^{32}$ estudaram a adsorção do glifosato sobre a goetita, utilizando espectroscopia no infravermelho com transformada de Fourier com reflectância total atenuada e espectroscopia de fotoelétrons de raios-X. Observaram que o glifosato forma preferencialmente complexos monodentados com a goetita pelo grupo fosfato, podendo formar complexos bidentados em $\mathrm{pH}$ neutro. $\mathrm{O}$ grupo carboxílico não se liga à goetita, porém, $\mathrm{o}$ grupo amina em $\mathrm{pH}$ baixo interage com os grupos carboxílicos e fosfato através de pontes de hidrogênio. Sheals et al. ${ }^{33}$ estudaram a coadsorção do $\mathrm{Cu}^{2+}$ e glifosato sobre a goetita em diversos valores de $\mathrm{pH}(3,0-9,0)$, utilizando as técnicas empregadas no trabalho anterior. Segundo estes autores, o grupo fosfato do glifosato liga-se à goetita na forma de um complexo monodentado e os grupos amina e carboxílico ligam-se ao $\mathrm{Cu}^{2+}$, formando um complexo com o anel de 5 membros. Em pH alto $(9,0)$, os grupos carboxílico e amina continuam ligados ao $\mathrm{Cu}^{2+}$, porém, o grupo fosfato não se liga mais à goetita. Dideriksen e Stipp ${ }^{34}$ estudaram a adsorção do glifosato sobre a goetita em meio de ácido nítrico, utilizando microscopia de força atômica. Observaram uma estrutura bem definida na qual o glifosato, através do grupo fosfato, interage com a goetita formando tanto complexos mono como bidentados. Uma outra estrutura, mas não tão bem definida, mostra uma possível formação de complexos tanto mono como bidentados, porém desta vez envolvendo tanto o grupo fosfato como o grupo carboxílico do glifosato. Pode-se concluir destes estudos que, de forma geral, o grupo fosfato do glifosato interage com $\mathrm{Fe}^{3+}$ e os grupos amina e carboxílicos ficam livres para interagirem com outros metais.

Miles e Moye ${ }^{29}$, estudando a adsorção do glifosato em óxidos de ferro e alumínio, obtiveram uma maior adsorção do glifosato no óxido de ferro que no óxido de alumínio. De Santana et al. ${ }^{27}$ estudaram pelo método de espectroscopia no infravermelho a interação entre glifosato e óxidos de ferro e alumínio e concluíram que em ambos os casos o grupo fosfato do glifosato estava interagindo com os metais.

$\mathrm{O}$ estudo da formação de complexos entre glifosato e diversos metais $\left(\mathrm{Ca}^{2+}, \mathrm{Cu}^{2+}, \mathrm{Mg}^{2+}, \mathrm{Al}^{3+}, \mathrm{Co}^{3+}, \mathrm{Fe}^{3+}\right)$ em solução aquosa tem ajudado a compreendermos melhor a interação do glifosafo com es- 
tes metais no solo. Subramaniam e Hoggard ${ }^{35}$ observaram que, em pH neutro, diversos metais $\left(\mathrm{Fe}^{3+}, \mathrm{Cu}^{2+}, \mathrm{Ca}^{2+}, \mathrm{Mg}^{2+}\right)$ formavam compostos insolúveis com o glifosato e os espectros infravermelhos destes compostos mostravam que os grupos fosfato, amino e carboxílico estavam envolvidos. Por outro lado, Barja et $a l .^{36}$, estudando a formação de complexos entre glifosato e diversos metais $\left(\mathrm{Fe}^{3+}, \mathrm{Al}^{3+} \mathrm{e}\right.$ $\mathrm{Co}^{3+}$ ), observaram que no estado sólido somente o grupo fosfato se liga aos metais e em solução o grupo carboxílico também participa. A partir destes dados, é possível considerar que a formação de compostos insolúveis entre glifosato e metais pode vir a ser uma maneira de eliminar o glifosato para não contaminar as águas subterrâneas. Sheals et al. ${ }^{37}$ e Undabeytia et al. ${ }^{38}$ estudaram a formação de complexos de $\mathrm{Cu}^{2+}$ com glifosato em diversos valores de $\mathrm{pH}$. Segundo estes autores o glifosato forma complexos com o $\mathrm{Cu}^{2+}$ do tipo $1: 1 \mathrm{e}$ todos os grupos do glifosato estão envolvidos.

\section{ADSORÇÃO COMPETITIVA ENTRE O GLIFOSATO E O FOSFATO}

Existem diversos estudos envolvendo a adsorção competitiva entre o glifosato e diferentes substâncias. No entanto, neste trabalho vamos discutir somente o caso da adsorção competitiva entre glifosato e fosfato, pois é o caso mais estudado, visto que adubos fosfatados são muito utilizados na agricultura e são adicionados aos solos em grande quantidade. $\mathrm{O}$ mecanismo de adsorção proposto para a interação glifosato-solo é similar ao mecanismo de ligação do fosfato inorgânico. A competição existente entre o fosfato inorgânico e o glifosato pelos sítios de adsorção foi demonstrada em laboratório, porém não tem sido medida no campo ${ }^{7}$.

Mcbride e Kung ${ }^{39}$, Gimsing e Boggaard ${ }^{40}$, Dion et al. ${ }^{41}$ e da Cruz et al. ${ }^{21}$ estudaram a adsorção competitiva entre glifosato e fosfato sobre óxido de ferro amorfo, goetita, ilita/caulinita e caulinita/bentonita/montimorilonita, respectivamente. Gimsing e Borggaard ${ }^{40}$ observaram que o fosfato provoca dessorção do glifosato, mas o inverso não ocorre. Mcbride e Kung ${ }^{39}$ verificaram que o glifosato foi completamente deslocado do óxido de ferro pelo fosfato. Por outro, lado Dion et al. ${ }^{41}$ e da Cruz et al..$^{21}$ demonstraram que o fosfato pode deslocar o glifosato das argilas, porém, isto foi atribuído à utilização de altas concentrações de fosfato, ou seja, pelo efeito de massas o glifosato é dessorvido das argilas pelo fosfato.

Prata et $a l .{ }^{42}$, estudando a adsorção e dessorção do glifosato em solos com diferentes concentrações de fósforo, verificaram que a extração do glifosato adsorvido pelo solo é maior quanto maior for a concentração de fósforo presente nesse solo. Observaram ainda que a adsorção do glifosato pelo solo ocorre devido à formação de complexos com os metais dos óxidos; tal processo está relacionado à capacidade dos solos em adsorver fosfato. Existe então uma competição entre o herbicida e os íons fosfato pelos sítios de adsorção específicos existentes no solo, porém, essa competição ocorre somente de forma significativa quando o valor de fósforo presente no solo é superior a $1.000 \mathrm{mg} \mathrm{dm}^{-3}$.

Estudando três diferentes tipos de solos chilenos, Kogan et al. ${ }^{43}$ observaram que a adsorção do glifosato pode estar relacionada à dinâmica do fosfato no solo; isso ficou claro para um dos três solos estudados.

Dion et al ${ }^{41}$ fizeram um estudo da adsorção competitiva entre glifosato e fosfato sobre solos com baixo conteúdo de matéria orgânica. Nesses rabalho observaram que o fosfato desloca o glifosato adsorvido, entretanto, Hubert et al. ${ }^{44}$ estudaram a lixiviação de glifosato em colunas de solos arenosos e argilosos e observaram que o fosfato não tem efeito na dessorção do glifosato, mas sim, o tamanho dos poros desses solos.

Da Cruz et al. ${ }^{21}$ estudaram a adsorção competitiva entre glifosato e fosfato sobre três diferentes solos do Paraná e concluíram que, quanto menor tanto a quantidade de argilas como a CTC dos solos, mais facilmente o fosfato desloca o glifosato.

Gimsing et al. ${ }^{25}$ estudaram a adsorção competitiva entre glifosato e fosfato em cinco diferentes solos e concluíram que, apesar de ambas as substâncias competirem pelos mesmos locais de adsorção, este efeito parece ser menos pronunciado que aquele observado no caso da goetita ${ }^{40}$.

A dessorção do glifosato pelo fosfato pode causar sérios problemas para os agricultores, como mostrado por Cornish ${ }^{45}$ que verificou, para o caso de tomates transplantados, uma diminuição significativa na produtividade.

\section{CONCLUSÕES}

A adsorção do glifosato pode ocorrer devido à presença de matéria orgânica, óxidos de ferro e alumínio e, também, devido às argilas que compõem os solos, sendo a fração inorgânica a de maior importância no processo de adsorção. O grupo fosfato do glifosato está envolvido na interação de metais constituintes dos solos e argilas. Uma vez adsorvido, o glifosato pode ficar como resíduo ligado permanecendo no ambiente até sua completa mineralização, que pode durar dias ou meses, dependendo das características do solo (textura, $\mathrm{pH}$, conteúdo de carbono orgânico, dentre outras). A dessorção do glifosato pelo fosfato nos solos depende de diversos fatores, tais como CTC, quantidade de argilas presentes, quantidade de fosfato e $\mathrm{pH}$ do solo. $\mathrm{O}$ fosfato pode deslocar o glifosato adsorvido sobre solos, podendo causar uma diminuição na produtividade de certas plantas.

\section{REFERÊNCIAS}

1. Amarante Jr., O. P.; Santos, T. C. R.; Brito, N. M.; Ribeiro, M. L.; Quim. Nova 2002, 25, 589.

2. Prata, F.; Lavorenti, A.; Comportamento de Herbicidas no solo: Influência da Matéria Orgânica, ESALQ/USP, 2000.

3. Nomura, H. S.; Hilton, H. W.; Weed Res. 1977, 17, 113.

4. Jacob, G. S.; Garbow, J. R.; Hallas, L. E.; Kimack, N. M.; Kishore, G. M.; Schaefer, J.; Appl. Envir. Microbiol. 1988, 54, 2953.

5. Javaroni, R. C. A.; Landgraf, M. D.; Rezende, M. O. O.; Quim. Nova 1999, $22,58$.

6. http://www.aenda.org.br/anews064.htm, acessada em Março 2005.

7. World Health Organization; Glyphosate: Environmental Health Criteria, Genebra: WHO, 1994, p. 159.

8. Amarante Jr., O. P.; Santos, T. C. R.; Brito, N. M.; Ribeiro, M. L.; Quim. Nova 2002, 25, 420.

9. Gruys, K. J.; Sikorski, J. A.; Inhibitors of Tryptophan, Phenylalanine and Tyrosine Biosynthesis as Herbicides, Dekker: New York, 1999.

10. Alibhai, M. F.; Stallings, W. C.; Proc. Natl. Acad. Sci. U.S.A. 2001, 98, 2944.

11. Schönbrunn, E.; Eschenberg, S.; Shuttleworth, W. A.; Schloss, J. V.; Amrhein, N.; Evans, J. N. S.; Kabsch, W.; Proc. Natl. Acad. Sci. U.S.A. 2001, 98, 1376.

12. Luchese, E.B.; Favero, L. O. B.; Lenzi, E.; Fundamentos da Química do solo-teoria e prática, $2^{\mathrm{a}}$ ed., Freitas Bastos Ed.: Rio de Janeiro, 2002.

13. Feng, J. C.; Thompson, D. G.; J. Agric. Food Chem. 1990, 1118.

14. Miano, T. M.; Piccolo, A.; Celano, G.; Senesi, N.; Sci. Total Environ. 1992, 123/124, 83.

15. Piccolo, A.; Celano, G.; Arienzo, M.; Mirabella, A.; J. Environ Sci. Health, Part B 1994, 29, 1105.

16. Gerritse, R. G.; Beltran, J.; Hernandez, F.; Aust. J. Soil Res. 1996, 34, 599.

17. Piccolo, A.; Celano, G.; Conte, P.; J. Agric. Food Chem. 1996, 44, 2442.

18. Undabeytia, T.; Cheshire, M. V.; McPhail, D.; Chemosphere 1996, 32, 1245.

19. Cheah, U. B.; Kirkwood, R. C.; Lum, K. Y.; Pest. Sci. 1997, 50, 53.

20. Prata, F.; Lavorenti, A.; Regitano, J. B.; Tornisielo, V. L.; Rev. Bras. Ci. Solo 2000, 24, 947.

21. Da Cruz, L. H.; De Santana, H.; Zaia, C. T. B. V.; Zaia, D. A. M.; J. Braz. Chem. Soc., submetido; Da Cruz, L. H.; Dissertação de Mestrado, Universidade Estadual de Londrina, Brasil, 2002.

22. Morillo, E.; Undabeytia, T.; Maqueda, C.; Ramos, A.; Chemosphere 2000, 40,103 . 
23. EPA EUA; Environmental fate and effects division. Pesticide environmental fate one line summary; glyphosate, Washington, D.C. May 6, 1993.

24. Glass, R. L.; J. Agric. Food Chem. 1987, 35, 497.

25. Gimsing, A. L.; Borggaard, O. K.; Bang, M.; Eur. J. Soil Sci. 2004, 55, 183.

26. Morillo, E.; Undabeytia, T.; Maqueda, C.; Ramos, A.; Chemosphere 2002, 47, 747.

27. De Santana, H.; Toni, L. R. M.; Benetoli, L. O. B.; Zaia, C. T. B. V.; Rosa Jr., M.; Zaia, D. A. M.; Geoderma, submetido; Rosa Jr., M.; Dissertação de Mestrado, Universidade Estadual de Londrina, Brasil, 2004.

28. McConnell, J. S.; Hossner, L. R.; J. Agric. Food Chem. 1985, 33, 1075.

29. Miles, C. J.; Moye, H. A.; J. Agric. Food Chem. 1988, 36, 486.

30. McConnell, J. S.; Hossner, L. R.; J. Agric. Food Chem. 1989, 37, 550

31. Dubbin, W. E.; Sposito, G.; Zavarian, M.; Soil Sci. 2000, 165, 699.

32. Sheals, J.; Sjöberg, S.; Persson, P.; Environ. Sci. Technol. 2002, 36, 3090.

33. Sheals, J.; Granström, M.; Sjöberg, S.; Persson, P.; J. Colloid Interface Sci. $\mathbf{2 0 0 3}, 262,38$.
34. Dideriksen, K.; Stipp, S. L. S.; Geochim. Cosmochim. Acta 2003, 18, 3313. 35. Subramaniam, V.; Hoggard, P.; J. Agric. Food Chem. 1988, 36, 1326.

36. Barja, B. C.; Herszage, J.; dos Santos Afonso, M.; Polyhedron 2001, 20, 1821.

37. Sheals, J.; Persson, P.; Hedman, B.; Inorg. Chem. 2001, 40, 4302.

38. Undabeytia, T.; Morillo, E.; Maqueda, C.; J. Agric. Food Chem. 2002, 50, 1918.

39. McBride, M.; Kung, K. H.; J. Soil Sci. Soc. Am. 1989, 53, 1668.

40. Gimsing, A. L.; Borggaard, O. K.; Clays Clay Miner. 2001, 49, 270.

41. Dion, H. M.; Harsh, J. B.; Hill Jr., H. H.; J. Radioanal. Nucl. Chem. 2001, 249, 385.

42. Prata, F.; Cardinali, V. C. B.; Lavorenti, A.; Tornisielo, V. L.; Regitano, J. B.; Scientia Agrícola 2003, 60, 175.

43. Kogan, M.; Metz, A.; Ortega, R.; Pesqu. Agropec. Brás. 2003, 38, 513.

44. Hubert, J. D. E.; Jonge, L. W. D. E.; Jacobsen, O. H.; Pest Manage. Sci. 2000, 56, 909.

45. Cornish, P. S.; Aust. J. Exper. Agric. 1992, 32, 395. 